\title{
A Solidão dos Moribundos: Falando Abertamente sobre a Morte
}

\author{
RACHEL AISENGART MENEZES ${ }^{l}$
}

\section{ELIAS, Norbert. A Solidão dos Moribundos. Tradução: Plínio Dentzien. \\ Rio de Janeiro: Jorge Zahar Editor, 2001. 107 p.}

Norbert Elias realiza o que propõe ao final de seu livro: falar abertamente sobre a morte. Para ele, "a morte não é terrível, passa-se ao sono e o mundo desaparece, mas o que pode ser terrível na atualidade é a dor dos moribundos, bem como a perda de uma pessoa querida sofrida pelos vivos" (p. 76). O autor demonstra mais uma vez - como já havia feito com a corte, a etiqueta, com os comportamentos e as mentalidades - que a sociedade é constituída por um conjunto de relações e que a experiência da morte difere de sociedade para sociedade. Escrito em 1982, A solidão dos moribundos é construído através de uma perspectiva histórica e social comparativa. Elias aponta que todos os grupos sociais e sociedades construíram idéias específicas e rituais correspondentes sobre a morte, que se tornam um dos aspectos do processo de socialização: idéias e ritos comuns unem pessoas e grupos. A morte, seus significados e o tratamento dado aos moribundos constituem parte de uma problemática relacionada à estrutura dos grupos e do tipo específico de coerção a que os indivíduos estão expostos.

Só o homem, dentre os seres vivos, sabe que vai morrer. Exatamente por essa consciência, durante milênios a proteção do aniquilamento foi a função central de grupos humanos. Há várias formas de os indivíduos lidarem com a idéia da finitude da vida: pode-se evitar a idéia da morte através da mitologização do final da vida, do encobrimento da idéia indesejada, pela crença na própria imortalidade ou encará-la como um fato da existência e ajustar a vida diante dessa realidade. Para Elias, atualmente há uma tendência à crença na imortalidade e ao afastamento da idéia da morte. Comparada a outros momentos históricos, a expectativa de vida tornou-se mais elevada, através dos avanços 
da medicina, da prevenção e do tratamento das doenças. A vida tornou-se mais previsível, exigindo maior grau de antecipação e de autocontrole. Diversamente dos séculos anteriores, quando o espetáculo da morte era corriqueiro e familiar, a morte passou a ser ocultada por trás dos bastidores da vida social. Os sentimentos e sua expressão se transformaram, a morte deixou de ser tema freqüente em conversas, como já o foi em outros tempos.

Contrapondo-se a Philippe Ariès - que, segundo Elias, "entende a história puramente como descrição", o que "não explica nada" - critica abertamente o espírito romântico manifestado em seu livro História da morte do Ocidente, no qual "olha com desconfiança para o presente inglório em nome de um passado melhor" (p. 19). A seleção de fatos de Ariès se baseia em opinião preconcebida, desconstruída por Elias. Quando comparada aos Estados-nação industrializados, a vida nos Estados medievais era apaixonada, violenta, incerta e breve. Morrer podia significar tormento e dor, pois antigamente havia menor possibilidade de alívio. Atualmente a medicina avançou - e segue avançando - no sentido de assegurar uma morte menos dolorosa e com maior alívio do sofrimento.

Elias concorda com Ariès no que se refere à difusão e expressão social do tema da morte, como, por exemplo, na literatura e na pintura. $\mathrm{O}$ fato de textos de outros tempos tratarem mais abertamente da morte, da sepultura, do aspecto e da decomposição dos cadáveres não significa um interesse mórbido pelo tema, mas uma sensibilidade distinta da atual. $\mathrm{O}$ autor considera que o historiador teria se limitado a uma historiografia descritiva, sem preocupação com a construção de um modelo teórico consistente.

Em comparação com o século XX, a morte era menos oculta, mais presente e familiar - o que não indica que fosse mais pacífica. $\mathrm{O}$ medo da morte foi intensificado especialmente no século XIV, com o crescimento das cidades e das epidemias: a violência era comum, a fome também. As pessoas temiam a morte e os religiosos reforçavam o medo: o sentimento de culpa e o temor da punição após a morte eram doutrina oficial. O envolvimento de uns na morte dos outros é que era diverso: muitas vezes o que reconfortava os moribundos era a presença de outras pessoas ao seu redor, mas isto dependia das atitudes. Tanto um moribundo podia ser assistido amorosamente por seus familiares, como os herdeiros podiam escarnecer abertamente do doente. Sem dúvida, a expressão em torno da morte era mais clara e freqüente, o que não demonstra de modo algum o bom passado nem o mau presente. 
Ao longo de sua obra, Norbert Elias apresenta e analisa o que ocorreu durante séculos para que distintos eventos fossem transformados socialmente: o processo civilizador. No curso do impulso civilizador, iniciado há cerca de quinhentos anos, as atitudes sociais das pessoas sofreram mudanças. Uma atitude atual é característica dessa transformação: o afastamento das crianças dos fatos da morte. Para Elias, esta seria uma indicação do processo de recalcamento da idéia da morte, seja no plano individual, seja no social. O encobrimento da morte na consciência humana é um processo antigo, a transformação ocorreu no que concerne à forma de ocultamento. Em tempos anteriores, fantasias coletivas constituíam o modo predominante no lidar com a idéia de morte. Com o processo de individualização ocorrido recentemente, fantasias pessoais de imortalidade têm preeminência sobre as coletivas: vivemos a ilusão da autonomia individual através de um padrão específico de individualização.

A morte é um problema dos vivos. Não é a própria morte que desperta temor, mas a imagem antecipada da morte na consciência dos vivos. O determinante na relação com a morte não é o processo biológico em si, mas a idéia que se tem de vida, de morte e da atitude associada a elas. Para Elias, não apenas a morte foi recalcada e sofreu transformações no decorrer do tempo, mas também a sexualidade. Do mesmo modo como o tema da morte é ocultado das crianças, a temática da vida sexual já foi ocultada. Para o autor, no século $\mathrm{XX}$ teria ocorrido um relaxamento dos tabus sexuais. Elias não se detém acerca do tema, mas pode-se apontar seu viés comprometido de gênero, ao tratar da solidão dos idosos em asilos: "Não estou pensando apenas nas necessidades sexuais, que podem ser muito ativas na extrema velhice, particularmente entre homens, mas também na proximidade emocional entre pessoas que gostam de estar juntas, que têm um certo envolvimento mútuo" (p. 86 - grifo meu).

O problema sociológico da morte torna-se mais claro através da compreensão das características das sociedades contemporâneas e das estruturas de personalidade associadas a elas. Nessas sociedades houve uma extensão da vida individual, uma expectativa de vida de cerca de 75 anos. Assim, a morte para um jovem é mais remota do que numa sociedade em que um homem de 40 anos é um velho. Elias levanta a hipótese de que talvez houvesse menos acidentes de trânsito se as pessoas não se afastassem tanto da idéia de morte. A segunda característica é a experiência da morte como 
estágio final de um processo natural ordenado, conseqüência direta de uma mudança nas concepções de natureza, ciência e medicina. A consciência atual da implacabilidade dos processos naturais é aliviada pelo conhecimento de que eles são - e busca-se que sejam mais e mais - controláveis. Hoje, mais do que nunca, esperamos e buscamos o adiamento da morte.

O grau relativamente alto de pacificação interna nessas sociedades seria a terceira característica. Assim, as pessoas, ao tentarem visualizar o processo de morte, provavelmente imaginam uma morte pacífica na cama, resultante de doença e/ou do envelhecimento e de sua conseqüente decadência física.

A estrutura de personalidade dos indivíduos transforma-se, vinculada à organização social no qual estão inseridos. As fórmulas rituais das antigas sociedades tornaram-se caducas e atualmente há um processo de informalização: homens não choram mais em público, fato diante do qual o autor se indaga visionariamente até quando as mulheres serão capazes de expressar suas emoções. Os rituais seculares foram esvaziados de sentimento e de significado, e novas formas ainda não foram encontradas.

A quarta característica é o alto grau de individualização, com a construção da auto-imagem do homo clausus. O "mundo interno" é construído como se fosse separado do "mundo externo". Elias demonstra como esta é uma característica das sociedades contemporâneas ocidentais, pois o "sentido é uma categoria social; o sujeito que lhe corresponde é uma pluralidade de pessoas interconectadas" (p. 63). O sentidoé construído social e historicamente, e a ilusão de que uma pessoa poderia ter um sentido exclusivamente seu é resultado de um permanente autocontrole e de um processo de individualização social. A resultante dessa equação pode conduzir a sentimentos de solidão e isolamento emocional. $\mathrm{O}$ autocontrole pode estar tão incorporado, de modo a gerar um bloqueio dos afetos e de impulsos espontâneos - o que pode variar dependendo da classe, gênero e geração. Deste modo, os moribundos, afastados da cena social, diante dos quais as pessoas se comportam com constrangimento, também podem se sentir embaraçados com seu estado e posição. Podem tender ao isolamento ou, pela proximidade da morte, tentar uma aproximação em busca de um sentido de suas vidas, de suas relações e de suas mortes. A busca do sentido para um indivíduo é vinculada ao significado que sua própria vida adquiriu para os de suas relações, seja através de seu trabalho, comportamento ou de sua própria pessoa. Na atualidade há movimentos de cuidados dos 
moribundos, como o alívio da dor e do desconforto físico. Contudo, esses cuidados são realizados em hospitais regidos por normas, o que pode resultar num modo de assistência impessoal.

Em tempo algum as pessoas morreram tão silenciosamente. Morre-se hoje higienicamente, sem odores, em hospitais cujas rotinas compõem uma estruturação social para o evento do morrer, tornando-o um acontecimento amorfo: "uma área vazia no mapa social" (p. 36). Há que se destacar o interesse de Elias pela medicina - curso que chegou a iniciar - e pelo papel do médico na sociedade contemporânea. Um dos grandes problemas atuais da formação e da prática médica seria, em suas palavras: “(...) o cuidado com as pessoas às vezes fica muito defasado em relação ao cuidado com seus órgãos" (p. 103 - grifo meu). Indo além, afirma que talvez os médicos não tenham clareza de que as relações de uma pessoa com as outras têm influência co-determinante tanto na gênese dos sintomas patológicos como no curso tomado pela doença.

O processo da morte somente pode ser compartilhado até certo limite: se uma pessoa que está a morrer sentir que deixou de ter significado para os outros, a solidão está configurada. A noção de solidão é ampla e manifesta-se de várias formas, como, por exemplo, na exclusão social, criando os "seres invisíveis", pessoas que vivem nas ruas das cidades, cujas existências são tomadas socialmente como sem significado. A dor e o sofrimento dos excluídos face à escassa possibilidade de identificação de outros com sua condição tornaram-se freqüentes. Assim, é "normal" que os jovens tenham dificuldade de se colocar no lugar dos mais velhos, como Elias exemplifica com um episódio de sua juventude. Assistindo a uma conferência, o autor pensou: "por que ele arrasta os pés assim? Por que não pode caminhar como um ser humano normal?". Imediatamente respondeu às próprias perguntas: "Não pode evitar, é muito velho".

Chegando à velhice, aos 85 anos, Elias entende como é difícil para os jovens compreenderem a situação dos mais velhos. Vários de seus conhecidos, ao saberem que nadava com regularidade e que apresentava boa desenvoltura física, diziam: "Impressionante! Como você ainda consegue se manter saudável? Na sua idade?", ou "Você ainda nada? Que maravilha!". Diante dessas observações, Elias diz: "Sinto-me um equilibrista, familiarizado com os riscos de seu modo de vida e razoavelmente certo de que alcançará a escada na outra ponta da corda, voltando tranquiilamente a seu devido tempo. Mas as pessoas que assistem a isso de baixo sabem que ele pode cair a qualquer 
momento e o contemplam excitadas e um tanto assustadas" (p. 81). A imagem circense do equilibrista aponta seu contato com os limites do envelhecimento e da proximidade - certamente maior do que a dos mais jovens - com a própria morte.

A solidão dos moribundos contém uma análise apurada das atitudes sociais diante da morte e do morrer. Em sua conclusão, Elias propõe: "Talvez devêssemos falar mais aberta e claramente sobre a morte, mesmo que seja deixando de apresentá-la como um mistério" (p. 77). O autor fala sobre a morte através de uma análise apurada e com rigor conceitual - eis o que propõe como alternativa ao ocultamento e ao silêncio em torno do tema.

\section{NOTAS}

${ }^{1}$ Mestre e doutora em Saúde Coletiva, Instituto de Medicina Social da UERJ. 